\title{
Comparison study of fault location on distribution network using PSCAD and DIgSILENT power factory by using matching approaches
}

\author{
Lilik J. Awalin', Tasnim², Tay Lea Tien ${ }^{3}$, Hadi Suyono ${ }^{4}$ \\ ${ }^{1,2}$ Universiti Kuala Lumpur, British Malaysian Institute, Malaysia \\ ${ }^{3}$ Universiti Sains Malaysia, Malaysia \\ ${ }^{4}$ Department of Electrical Engineering, Faculty of Engineering, Universitas Brawijaya, Indonesia
}

\begin{tabular}{|c|c|}
\hline Article Info & ABSTRACT \\
\hline Article history: & \multirow{11}{*}{$\begin{array}{l}\text { This paper presents the comparative study between PSCAD and DIgSILENT } \\
\text { in order to detect fault location on underground distribution network. If a } \\
\text { fault occurs in the distribution network, it will generate the voltage dips and } \\
\text { over current. It is possible to record the signal output in the primary } \\
\text { substation. However, for the research purpose, some of the researcher may } \\
\text { use different simulation program. The simulation program may have } \\
\text { different performance to generate voltage and current signal when fault } \\
\text { simulated. So, it is important to observe the performance of each simulation } \\
\text { software. Due to every simulation software may have different advantages, } \\
\text { this paper will observe the accuracy of fault distance calculation based on } \\
\text { simulation data on the distribution model and when all types of fault are } \\
\text { applied to the different simulation program, namely PSCAD and DIgSilent. } \\
\text { The matching approach was adopted to calculate the fault distance. To } \\
\text { observe the performance of the simulation program, the distance error } \\
\text { calculation for every type of fault are compared. By using a matching } \\
\text { approach, the PSCAD simulation program produces more accurate fault } \\
\text { distance compare with DIgSILENT. However, it may contribute different } \\
\text { result if different method and tested network applied. }\end{array}$} \\
\hline Received Apr 2, 2019 & \\
\hline Revised Jul 9, 2019 & \\
\hline Accepted Aug 1, 2019 & \\
\hline Keywords: & \\
\hline DIgSILENT power factory & \\
\hline simulation software & \\
\hline & \\
\hline Fault location & \\
\hline Matching approach & \\
\hline PSCAD simulation program & \\
\hline
\end{tabular}

Copyright $@ 2020$ Institute of Advanced Engineering and Science.
All rights reserved.

Copyright $@ 2020$ Institute of Advanced Engineering and Science.
All rights reserved.

\section{Corresponding Author:}

Lilik J. Awalin,

Universiti Kuala Lumpur, British Malaysian Institute,

Batu 8, Jalan Sungai Pusu 53100 Gombak, Selangor, Malaysia.

Email: lilik@unikl.edu.my

\section{INTRODUCTION}

The main objective of an electric power supply is to satisfy the customer requirements with a reasonable assurance of continuity and quality. In order to achieve the required, reliability of power distribution will achieve if normal condition always occurs in the distribution network. However, it is impossible to achieve due to so many factors such as environment or aging of the component which cause the fault. In order to maintain the reliability of the power supply, detection of fault is a very important part. Many researchers have been improved methods and also consider any simulation program to observe the pattern of voltage dips and current swell as reflected in the fault occurrence. In a power system, there are several software that's been used to simulate the power system network in terms of power load flow, short-circuit analysis, protection, reliability and harmonics/power quality.

Some simulation programs have emerged that can be used in research, specifically in the field of electric power. Several simulation programs such as DIgSILENT and PSCAD are simulation programs that are widely used in research. Previous research [1-20] had used PSCAD software and [21-26] utilize DIgSILENT to simulate fault current at Busbar and between subsection lines to estimate fault distance. When 
a fault occurred, the voltage dips and over current measured from the recorded node are utilized to calculate percentage fault distance error.

DIgSILENT Power Factory is used to record data handling, to build modelling capabilities and minimizing project execution costs and training. So, DIgSILENT is one of the simulation program which helpful for power flow analysis, wind power, industrial grids and distributed generation in terms of application of new technologies. This software also serves as the ideal complement to study load flow, steady state voltage stability, dynamic and transient behavior of power systems. The power flow analyzes the current flows to the branches and voltage magnitude based on the performance of active/reactive power. It simulates the best possible values for optimized a user for specified objective. The power flow is one of the most fundamental concepts in power system in transmission and distribution network. It is highly required to design an accurate and stable power flow solver for the interconnected system. DIgSILENT is one of the software that provide powerful solver that is used by the researcher [21-26].

Another popular for the research works is PSCAD simulation program. It also simulation program which applies in electrical engineering field. PSCAD is used by engineers, researchers and students plan, and design, develop new concepts and testing ideas of what happened when equipment failed. PSCAD can conduct some related studies such as fault in power system, relay testing that can test physical protection and control equipment. PSCAD can conduct studies about how to measure the voltage magnitude and angle in a power system due to a lightning strike. PSCAD also one of the simulation program which able to record the real time data or signal in in nanoseconds [1-20].

On the other hand, the problem of fault detection in the electric power distribution system also forces some researcher to improve methods in order to increase the accuracy of fault detection. Some methods such as impedance-based [1-2], matching approaches [3-6], travelling waves [7-11], Arduino technology and optimization [12-13] have become developed and increased the level accuracy of fault localization. Due to so many fault location methods have improved, some of paper literature review also helps to classify the fault location method, such as in paper [16-19].

Based on the above discussion, this paper presents the comparative study of fault distance calculation using matching approach based on the simulation data from DIgSILENT and PSCAD. By adopting the voltage and current magnitude, the fault distance will tested on the non-homogeneous distribution network to evaluate the accuracy of fault distance. To make easier the understanding of the reader, this paper is organized as follows: in Section 2 is the overview of the research method. Section 3 discussed the overview of tests network and followed by results and discussion in Section 4. Finally, conclusions are presented in Section 5.

\section{RESEARCH METHOD}

Based on the overview of fault location methods, matching appoarch is one of the method which claim able to produce the accurate result [3-6]. This method was utilizes voltage and current magnitude to calculate the fault distance. It values is one of the impact of fault occurance. A measurement that called data recorded device will measure voltage dips output signal because to fault at the measurement node. As mention it in introduction, matching approach is one of the linier method of fault distance estimation. The basic principle of fault distance formula is determined by assuming that the length between point $p-q$ is the represent the cable which fault is assumed occur this line of cable. It can illustrate in Figure 1.

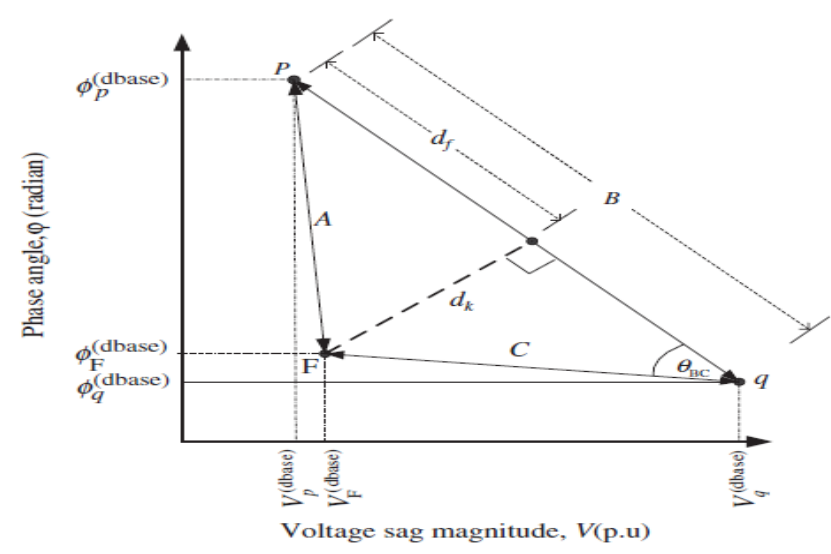

Figure 1. Linier method of fault distance 

length, Fd.

The calculation will be done by finding the shortest distance, $d_{k}$, fault distance, $d_{f}$, and actual

$$
\begin{aligned}
& d_{k}=|\sin \theta \mathrm{BC} \times \mathrm{C}| \\
& d_{f}=\sqrt{ } A^{2}-d k^{2} \\
& \mathrm{Fd}=|\mathrm{df} \times 1 \mathrm{p}-\mathrm{q}| / \mathrm{B}
\end{aligned}
$$

Where:

$$
\begin{aligned}
& \theta B C=\cos -1\left[\left(B^{2}+C^{2}-A^{2}\right) /(2 \times \mathrm{B} \times \mathrm{C})\right](3.5) \\
& \mathrm{A}=\sqrt{ }\left(\theta p(\text { dbase })-\theta F(\text { meas }) 2+\left(V F(\text { meas })-V P(\text { dbase })^{2}\right.\right. \\
& \mathrm{B}=\sqrt{ }\left(\theta p(\text { dbase })-\theta q(\text { dbase }) 2+\left(V q(\text { meas })-V P(\text { dbase })^{2}\right.\right. \\
& \mathrm{C}=\sqrt{ }\left(\theta F(\text { dbase })-\theta q(\text { meas }) 2+\left(V q(\text { meas })-V F(\text { dbase })^{2}\right.\right. \\
& \mathrm{L} p-q \text { is the length of cable }(\mathrm{Km}) .
\end{aligned}
$$

The advantage of PSCAD software is able to simulate the dynamic condition of electrical current and voltage during the fault occurrence, such as single phase to ground fault, line to line fault, double line to ground fault and three phase fault. PSCAD provide many models of the components which support to conduct the research, such as PI model of cable, transformer, FFT (Fast Fourier Transform), digital operation, kind of relay and some of electric machines, etc [15].

It consist of two parts which are the basic framework and the user-defined module. The basic framework are components in the library which have the basic function such as power supply, transformer, line or cable, and measurement element. The user-defined consist of the arc grounded model, the ground fault model [20]. Parameters of the tested network are collected such as type of cable, length of cable, load data for each node and input from source and transformer. The source in the system that will be used in this research study is $132 \mathrm{kV}$ with frequency $50 \mathrm{~Hz}$. Then the voltage will be stepping down to $11 \mathrm{kV}$. A transformer is connected in delta-Wye connection.

After that, the parameter value then was inserted into the DIgSILENT simulation software to execute for short circuit analysis. All of the type of fault is injected into the line and Busbar. Then, calculated using matching approach method will be done to obtain the accuracy of fault distance and then compared with the calculation result based on data from PSCAD. Flowchart of the Working Research is shown in Figure 2.

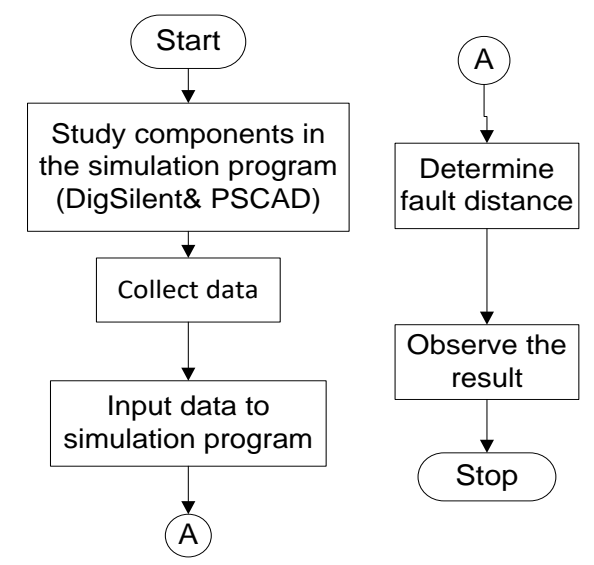

Figure 2. Flowchart of the Working Research

\section{OVERVIEW OF TESTED NETWORK}

The tested network, shown in Figure 3, consist of $132 \mathrm{kV}$ source and one unit scale down transformer $132 \mathrm{kV}$ to $11 \mathrm{kV}$. The distribution network has 19 loads/nodes which is divided in 3 branches. Single line diagram is presented to describe the tested network. Measurement node were placed close with the transformer or call as primary substation. The actual line are three-phase underground distribution system. The fault simulated on each section or between feeder to feeder points. 


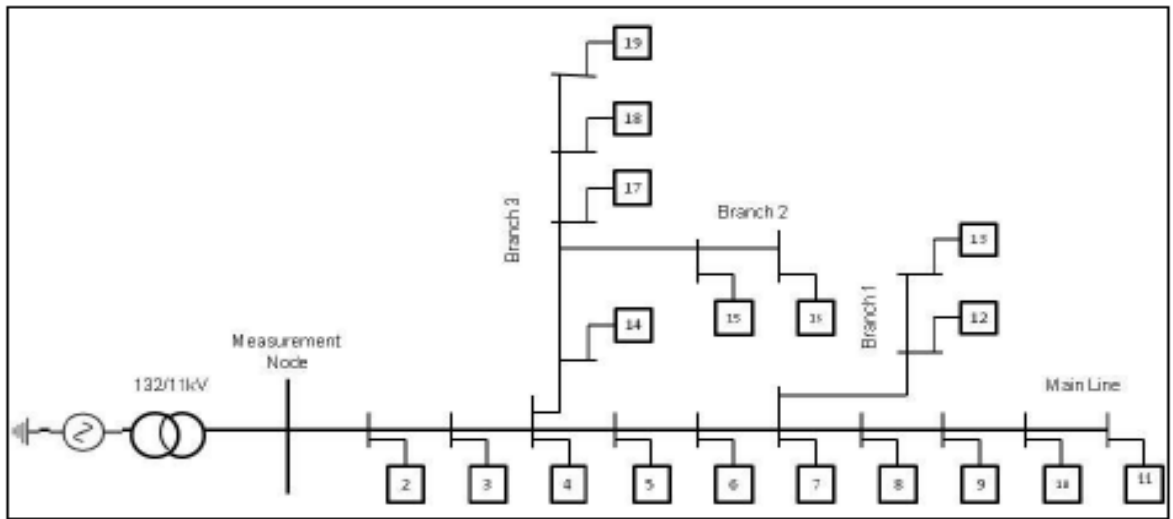

Figure 3. Tested Network

Based on the actual data from Tenaga Nasional Berhad Malaysia, the tested network then was constructed in PSCAD and DIgSILENT software as shown in Figure 4 and Figure 5 respectivelly. It will to run the short circuit simulation at every line between two nodes. In the PSCAD simulation program. The length of line which have different impedance line values are represent non homogeneous distribution network.

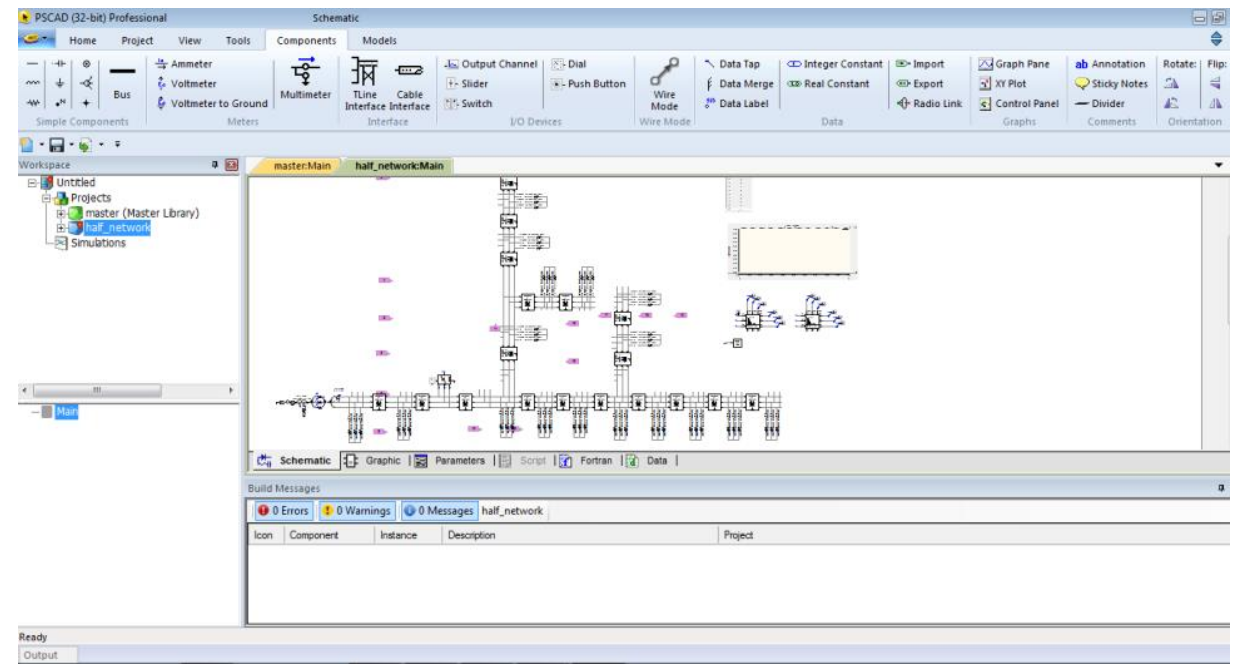

Figure 4. The tested network in PSCAD

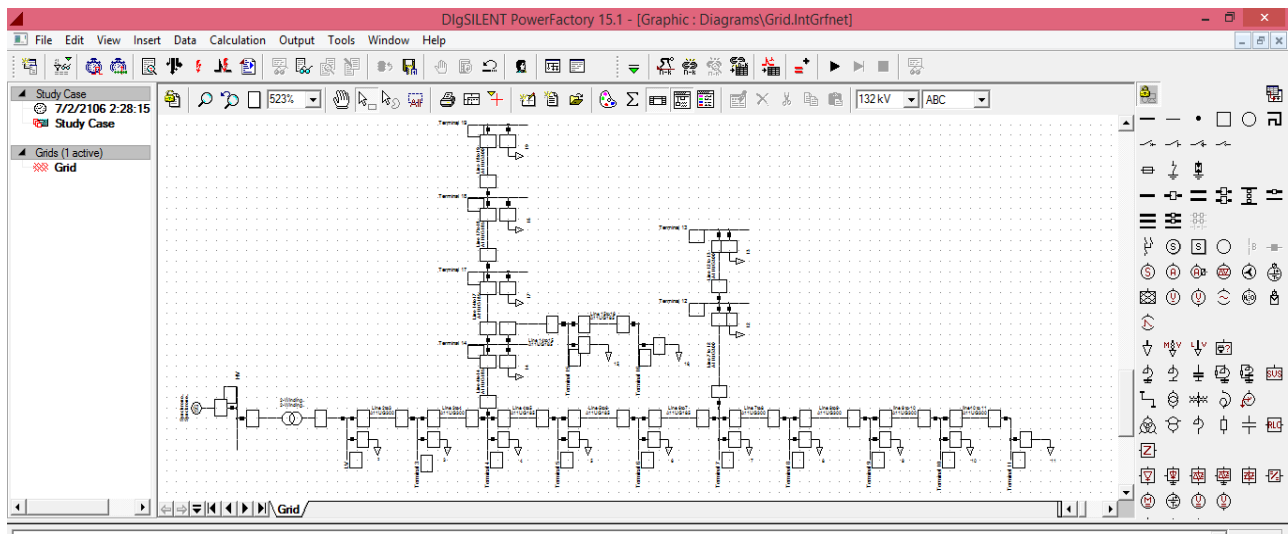

Figure 5. The tested network in DIgSILENT 


\section{RESULTS AND ANALYSIS}

In this section, discussions and analysis on accuracy of fault distance will also be explained. The results will cover for each type of fault namely, single line to ground fault, double line fault, double line to ground fault, and three phase to ground fault. The accuracy of fault distance are calculated by considering the differences between the actual fault distance simulated in PSCAD and DIgSILENT and obtain result of fault distance calculation. The the differences result are devided by the total length length of cable. The accuracy of fault distance were simulated at the midpoint for every section.

\subsection{Comparison of fault distance based on PSCAD and DIgSILENT simulation Program}

A comparison of accuracy based on simulation results from PSCAD and DIgSILENT is discussed in this section. The obtained result from estimation fault distance error for single line to ground fault, line to line fault, double line to ground fault, and three phase fault from both software are presented in the graph. The blue line in the graph represented the values of fault distance error based on PSCAD simulation program. And the red of the dotted line in the Figure 6-8 represented accuracy of fault considering DIgSILENT.

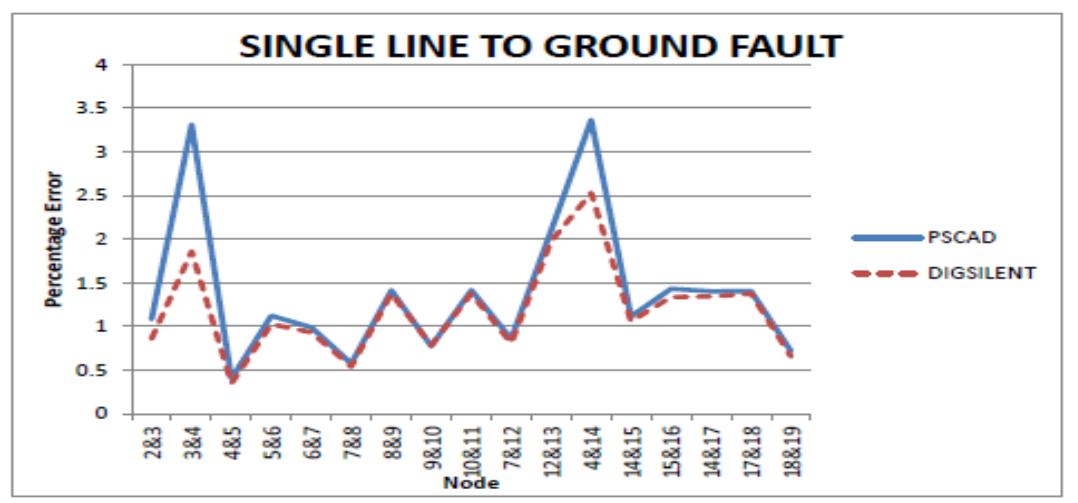

Figure 6. Estimation error of fault distance for SLGF

The estimation error of fault distance for Single Line to Ground Fault is shows inFigure 6. The obtain result of fault occurs in section $4 \& 5$ and $7 \& 8$ is having good performance in PSCAD and DIgSILENT software since the section is short distance. The length of the cable for section $4 \& 5$ is $0.14 \mathrm{~km}$ while section $7 \& 8$ is $0.2 \mathrm{~km}$. The worse performance of fault distance calculation is obtained in section $4 \& 14$ and $3 \& 4$ for both simulation programs. Both sections were chosen to represent long cable in each subsection which have real length are $1.29 \mathrm{~km}$ and $1.25 \mathrm{~km}$ respectively.

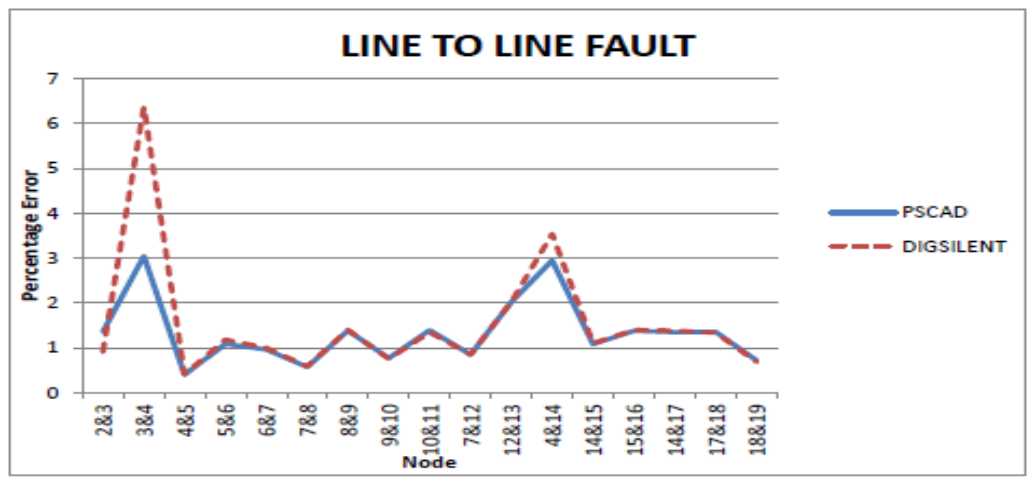

Figure 7. Estimation error of fault distance for LLF

All fault distance calculation result for Line to Line Fault represented in Figure 7. It can be seen that the highest values of estimation error are between section $3 \& 4$ while the lowest is between section $4 \& 5$. The 
fault distance error in the PSCAD software for section $3 \& 4$ is $3.0417095 \%$, while for section $4 \& 5$ is $0.396686 \%$. It shows some difference value from DIgSILENT software which is $6.370873 \%$ for section $3 \& 4$ and $0.406551 \%$ for section $4 \& 5$. From the graph, the other sections obtained slightly similar result for fault distance error when line to line fault occur in the tested network. The error obtained is higher because the section has the longest cable between the node 3 and 4 which is $1.25 \mathrm{~km}$.

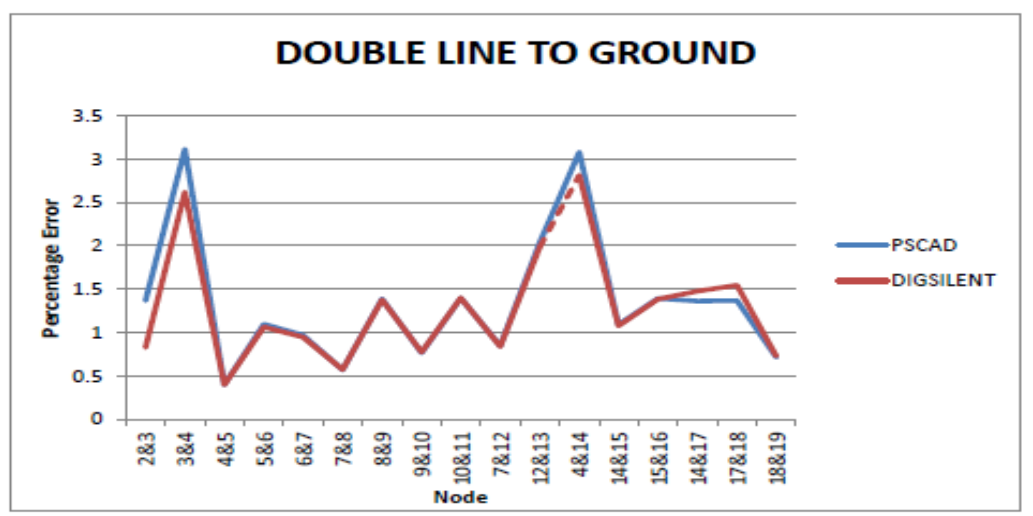

Figure 8. Estimation error of fault distance for DLGF

Figure 8 illustrates the estimation error fault fault distance for Double Line to Ground Fault. The result shows that the percentage error of fault distance in DigSILENT occurs in line $4 \& 14$ is the highest since the cable between line $4 \& 14$ is the length which is $1.29 \mathrm{~km}$. Meanwhile, in PSCAD software shows that the highest fault distance error happens at line $3 \& 4$ where it also has the longest cable lie between node 3 and 4 which is $1.25 \mathrm{~km}$. In case the blue line doesn't appear, it due to the result based on DIgSILENT and PSCAD are same. When the double line to ground fault occur, the shortest fault distance error will happen in line $4 \& 5$. This is because the line has very short cable compare to the other subsection in the tested network.

Figure 9 shows that the result obtained from PSCAD and DIgSILENT for three phase to ground fault. It can be seen that PSCAD and DIgSILENT did not have so much different when the three phases to ground fault occur. From the Figure 9, it can be seen that the highest fault distance error occur at line $3 \& 4$ and $4 \& 14$. Both lines have the longest cables in the tested distribution network. It shows that the percentage error is having effect mostly on the length of cable which have the long distance from the substation.

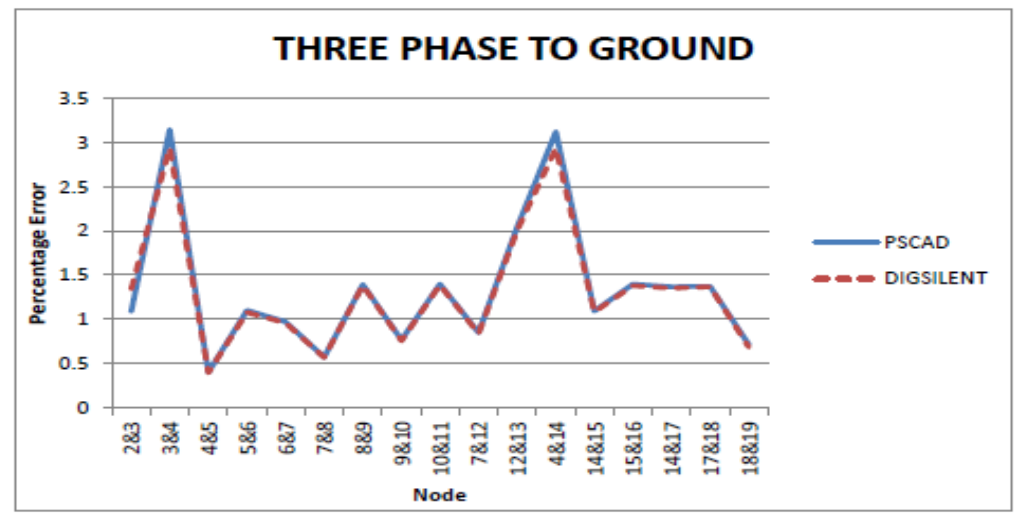

Figure 9. Fault distance error for each section for three phases to ground fault

Generally, most of the percentage of fault distance error is less than 5\%. It is mean that the error for both simulation software is acceptable. Based on length of line/cable of the tested network, the longer length will obtain a higher error while the shorter length will obtain less error. To be compared from both software, DIgSILENT obtained small value of error than PSCAD. Thus, DIgSILENT software is more accurate than PSCAD. 


\section{CONCLUSION}

This paper was addressed the comparative study on fault distance calculations by using different simulation program namely, PSCAD and DIgSILENT. Based on voltage and current which generated by PSCAD and DIgSILENT simulation program, the values submitted to the formulation of fault distance.The formulation from matching approach was adopted to calculate the fault distance. The obtain result shows that the performance of the percentage error of fault distance by using PSCAD and DIgSILENT are acceptable. However, the accuracy of fault distance for every type of fault has a different result. The percentage error from DIgSILENT gives smaller value than PSCAD for SLGF, DLGF and three phases to Ground Fault. However, different performance of accuracy is shown for LLF. In this type of fault, consideration of PSCAD simulation program generates better accuracy than DIgSILENT. Generally, this work have been successfully generate various accuracy of fault distance based on different simulation program namely PSCAD and DIgSILENT.

\section{ACKNOWLEDGEMENTS}

The authors would like to express appreciation for the support from the Universiti Kuala Lumpur, British Malaysian Institute through research grant of UniKL/CoRI/str117073.

\section{REFERENCES}

[1] Awalin, L. J., et al. "A Novel of Fault Localization Method to Determine Fault Distance for Single Line to Ground Fault in the Distribution Network." Applied Mechanics and Materials. Vol. 785. Trans Tech Publications, 2015.

[2] Girgis, Adly A., Christopher M. Fallon, and David L. Lubkeman. "A fault location technique for rural distribution feeders." IEEE Transactions on Industry Applications 29.6 (1993): 1170-1175

[3] Mokhlis, H., et al. "A comprehensive fault location estimation using voltage sag profile for non-homogenous distribution networks." International Review of Electrical Engineering 5.5 (2010): 2310-2316.

[4] Mokhlis, H., et al. "Fault location estimation method by considering measurement error for distribution networks." International Transactions on Electrical Energy Systems 24.9 (2014): 1244-1262.

[5] Li, Haiyu, Ahmad S. Mokhar, and Nick Jenkins. "Automatic fault location on distribution network using voltage sags measurements." CIRED 2005-18th International Conference and Exhibition on Electricity Distribution. IET, 2005

[6] Awalin, Lilik Jamilatul, Hazlie Mokhlis, and A. H. A. Halim. "Improved fault location on distribution network based on multiple measurements of voltage sags pattern." 2012 IEEE International Conference on Power and Energy (PECon). IEEE, 2012.

[7] R. H. R. Salim, M. Filomena, A. D. Rezende Caino de Oliveira, K. Bretas, A. S., "Extended Fault-Location Formulation for Power Distribution Systems," Power Delivery, IEEE Transactions on, vol. 24, pp. 508-516, 2009.

[8] H. X. Fengling, Yu. Al-Dabbagh, M. Yi, Wang, "Locating Phase-to-Ground Short-Circuit Faults on Radial Distribution Lines," Industrial Electronics, IEEE Transactions on, vol. 54,pp. 1581-1590, 2007

[9] Mustapha, Abdul Hadi Bin Mustapha, et al. " Fault location identification of double circuit transmission line using discrete wavelet transform, Indonesian Journal of Electrical Engineering and Computer Science (IJEECS) 15.3 (2019): 1356-1365.

[10] Hashim, Mimi Nurzilah, Muhammad Khusairi Osman, Mohammad Nizam Ibrahim, Ahmad FaridAbidin, and Ahmad Asri Abd Samat. "A comparison study of learning algorithms for estimating fault location." Indonesian Journal of Electrical Engineering and Computer Science (IJEECS) i 6 (2017): 464-472.

[11] H. K. K. Abolfazl Jalilvand, Hadi Fotoohabadi, "High Impedance Fault Detection Using Duffing Oscillator and FIR Filter," International Review of Electrical Engineering, vol. 5,p. 10, 2010.

[12] Hashim, Mimi Nurzilah, Muhammad Khusairi Osman, Mohammad Nizam Ibrahim, Ahmad FaridAbidin, and Ahmad Asri Abd Samat. "A comparison study of learning algorithms for estimating fault location." Indonesian Journal of Electrical Engineering and Computer Science (IJEECS) 6 (2017): 464-472.

[13] Karupiah, S., et al. "Prediction of overcurrent relay miscoordination time using urtificial neural network." Indonesian Journal of Electrical Engineering and Computer Science (IJEECS)14.1 (2019): 319-326

[14] DigSILENT Power Factory, Version 14.1 User's manual online edition. Gomaringen, Germany,2011.

[15] Monitiba HVDC Research Centre "PSCAD/EMTDC: Electromagnetic Transients Program Including DC Systems, 1994.

[16] Awalin, Lilik Jamilatul, Hazlie Mokhlis, and AH Abu Bakar. "Recent developments in fault location methods for distribution networks." Przeglad Elektrotechniczny 88, no. 12 A (2012): 206-212.

[17] Saha, Murari Mohan, et al. "Review of fault location techniques for distribution systems." Power systems and communications infrastructures for the future, Beijing (2002).

[18] Goh, Hui Hwang, Sy yi Sim, Mohamad Amirul Hafiz Mohamed, Abdul Khairi Abdul Rahman, Chin Wan Ling, Qing Shi Chua, and Kai Chen Goh. "Fault Location Techniques in Electrical Power System: A Review." Indonesian Journal of Electrical Engineering and Computer Science (IJEECS) 8, no. 1 (2017): 206-212. 
[19] Awalin, Lilik Jamilatul, et al. "Fault Distance Identification Using Impedance and Matching Approaches on Distribution Network." Indonesian Journal of Electrical Engineering and Computer Science (IJEECS) 8.3 (2017): 770-778.

[20] $\mathrm{Xu}$, Bo, Jun Zhang, and $\mathrm{Xu}$ Cai. "The Simulation Platform of $10 \mathrm{kV}$ Distribution Network Based on PSCAD/EMTDC." Advanced Materials Research. Vol. 354. Trans Tech Publications, 2012.

[21] Han, Yi, Xuehao Hu, and Dongxia Zhang. "Study of adaptive fault current algorithm for microgrid dominated by inverter based distributed generators." In The 2nd International Symposium on Power Electronics for Distributed Generation Systems, pp. 852-854. IEEE, 2010.

[22] Zayandehroodi, Hadi, Azah Mohamed, Hussain Shareef, and Marjan Mohammadjafari. "Determining exact fault location in a distribution network in presence of DGs using RBF neural networks." In 2011 IEEE International Conference on Information Reuse \& Integration, pp. 434-438. IEEE, 2011.

[23] Javadian, Seyed Ali Mohammad, M-R. Haghifam, and Nazkhanom Rezaei. "A fault location and protection scheme for distribution systems in presence of dg using MLP neural networks." In 2009 IEEE Power \& Energy Society General Meeting, pp. 1-8. IEEE, 2009.

[24] Krishnathevar, Ramar, and Eng Eng Ngu. "Generalized impedance-based fault location for distribution systems." IEEE transactions on power delivery 27, no. 1 (2011): 449-451.

[25] Mirzaei, Maryam, Mohd Zainal Abidin Ab. Kadir, Hashim Hizam, and Ehsan Moazami. "Comparative analysis of probabilistic neural network, radial basis function, and feed-forward neural network for fault classification in power distribution systems." Electric Power Components and Systems 39, no. 16 (2011): 1858-1871.

[26] Dehghani, Farzad, and Hamid Nezami. "A new fault location technique on radial distribution systems using artificial neural network." (2013): 0375-0375. 